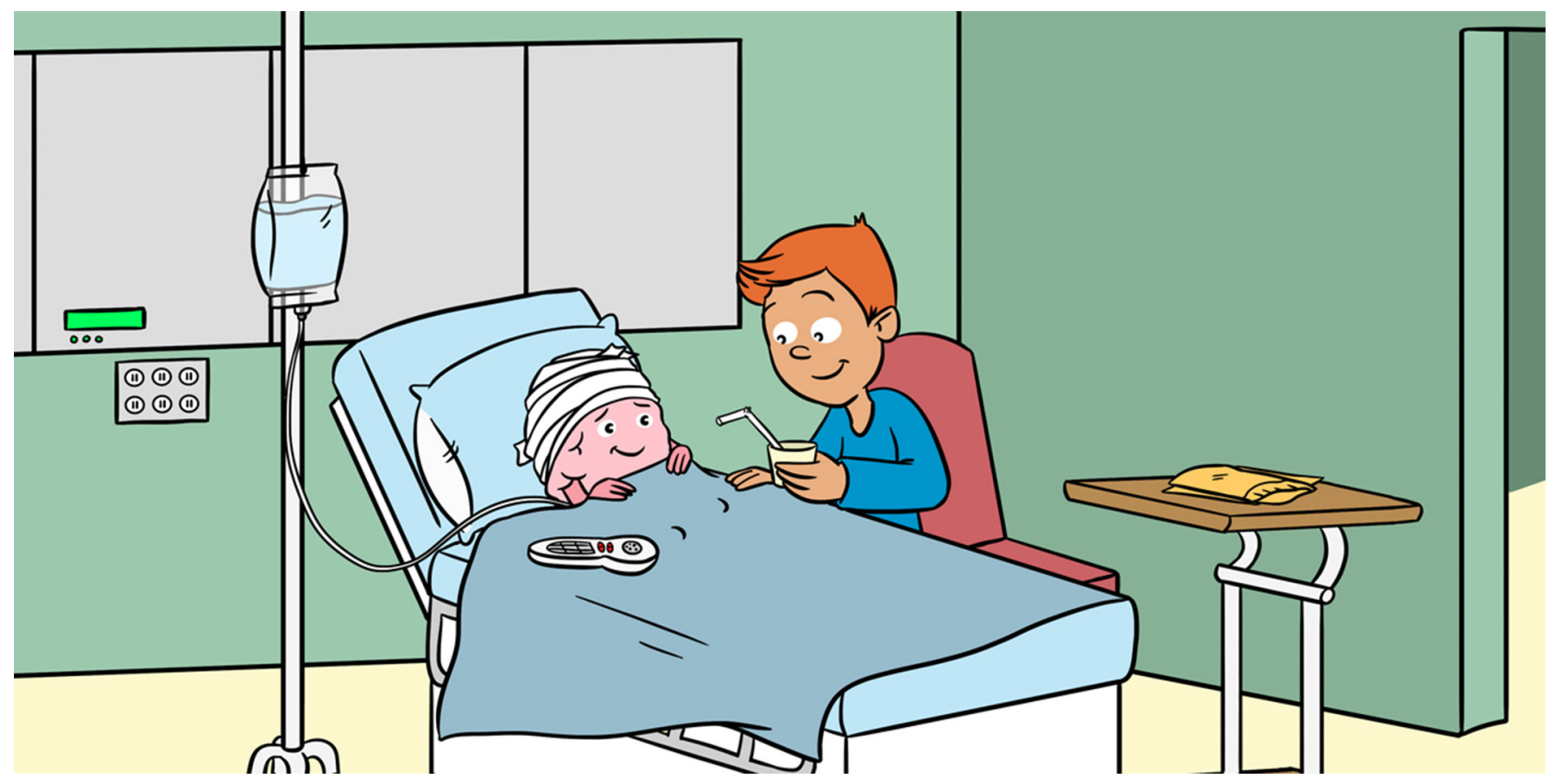

\title{
BRAIN SURGERY TO TREAT SEIZURES
}

\section{Fady Girgis *}

Department of Neurosurgery, University of Calgary, Calgary, AB, Canada

YOUNG REVIEWERS:

ORGANIZATION FOR

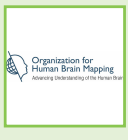

HUMAN

BRAIN

MAPPING

AGE: 8-15

PINAKI

AGE: 9
Seizures can happen when the electricity in the brain is not working properly. Seizures can cause people to shake and lose awareness, which can be very scary and prevent people from living normal lives. When medications do not work to take away the seizures, sometimes brain surgery can be done to treat them. This procedure starts when doctors take a special picture of the brain to see the area causing the seizures. Then they make an opening in the patient's head to fix the problem in the brain. Part of the brain can be removed, or a special device that stimulates the brain with electricity can be implanted. It is important for everyone who has seizures or who knows someone with seizures to be aware of the option of surgery, because sometimes surgery can be a cure for the seizures.

\section{WHAT ARE SEIZURES, AND HOW CAN WE TREAT THEM?}

Normally, our brain cells communicate with each other using electricity. This is similar to the electricity that powers your television and computer, but at a much lower strength. A seizure can occur if there is too much electricity flowing throughout the brain. 


\section{BRAIN SURGERY}

When a special doctor, called a neurosurgeon, makes an opening in the head and performs an operation on the brain.

\section{TEMPORAL}

\section{LOBECTOMY}

Removing a part of the brain called the "temporal lobe," often to treat seizures.
About 1 in every 100 people will have seizures during their life. Seizures can occur for many different reasons. These include irritation to the brain by a tumor, a mistake when the brain is developing in babies, or incorrect amounts of salt or sugar in the body. There are also many types of seizures, and different people can have seizures with very different symptoms. For example, some people will shake, some will lose awareness, and some seizures are so short that people do not even know they had one! Also, seizures can cause a certain part of the brain to briefly stop working. For example, if a seizure happens in the brain area that makes a person talk, that person would not be able to talk during the seizure.

Seizures can make it difficult to lead a normal life. Often, people are unable to drive or work because of the risk of having a seizure. Also, seizures can be scary, not only for the person having them, but also for people who witness the seizure, because they do not know what is happening. To treat seizures, doctors can use medications that return the electrical signals in the brain to normal. But, in some people, medications do not work. In fact, about 3 out of every 10 people with seizures will not respond to medications. In these cases, sometimes brain surgery can help.

About 100 years ago, a brain surgeon in England discovered that seizures could sometimes be cured if he removed the part of the brain that caused them. Several decades later, in the 1930's, a Canadian brain surgeon named Dr. Penfield pioneered a special type of surgery. This was called temporal lobectomy, and it is used to treat a common type of seizure. It involves removing a part of the brain called the temporal lobe. He tried this operation in many people and found that it often cured their seizures. Because of this, he became one of the most famous brain surgeons in history. Thanks to his work, we routinely treat many people using brain surgery today.

\section{WHAT IS BRAIN SURGERY?}

Brain surgery is when a special doctor, called a neurosurgeon, does an operation on the brain. This operation involves making an opening in the patient's head! The surgeon must trim the person's hair, make a cut in the skin, and then drill an opening into the skull. Once a piece of the skull is removed, the surgeon can then see the brain and try to fix the problem. After the work on the brain is complete, the surgeon puts the piece of bone back and attaches it to the skull using metal screws. Finally, a needle and thread are used to sew the skin back together, and the operation is complete.

Most of the time people are asleep when they have surgery, but with some brain operations people can actually be awake. While that may sound scary, amazingly the brain does not feel any pain. So, it would be like being at the dentist when he or she numbs a part of your mouth 
Figure 1

An MRI image of a person's brain. This image is looking up through the bottom of the skull, and you can see the eyes at the top MRI can be used to determine whether certain areas of the brain are not working properly and may be causing seizures.

\section{ELOQUENT}

When describing the brain, it refers to parts of the brain that have important functions, such as talking and moving.

\section{MAGNETIC}

RESONANCE

IMAGING (MRI)

A special picture that can show parts of the brain that are not working properly.

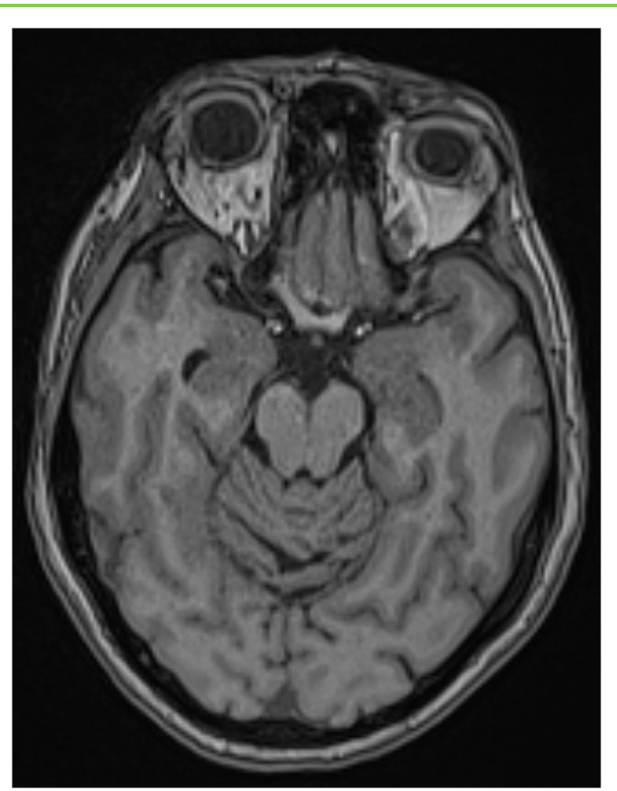

Figure 1

to fix a toothache. Even though you are awake, you cannot feel what is happening inside your mouth. The reason some brain operations are done when the person is awake is so that the surgeon can protect important or eloquent parts of the brain. These eloquent parts include brain areas that control movement and talking, which are important functions in our everyday lives. So, when the surgeon is operating close to these areas, he or she may prefer to have the patient awake so that the eloquent brain areas can be identified and protected.

\section{WHEN SHOULD WE DO SURGERY TO TREAT SEIZURES?}

We only do brain surgery to treat seizures in certain cases. First, doctors need to ensure that the seizures are not treatable with medications. If medications can stop the seizures, then surgery is not needed. Second, the seizures need to be disabling for the person, meaning that they are making the person's life extremely difficult. If a person is not having seizures very often, or is not bothered by them, then that person does not need an operation. Third, doctors need to ensure that doing an operation has a good chance of curing the seizures. One of the main ways doctors do this is by taking a special picture of the brain using a method called magnetic resonance imaging, or MRI (Figure 1). An MRI can show if certain parts of the brain are not working properly and are causing seizures. Doctors can then decide if an operation can fix the problem and stop the seizures.

\section{WHAT TYPES OF BRAIN SURGERY ARE DONE FOR SEIZURES?}

There are two general types of surgery that can be done for seizures. The first type includes operations to help determine where the seizures 
Figure 2

A picture of the brain showing a part called the temporal lobe (orange) that can be removed to treat seizures. The brain is pictured from the side, as if the person is looking to the left. This operation is called a temporal lobectomy.

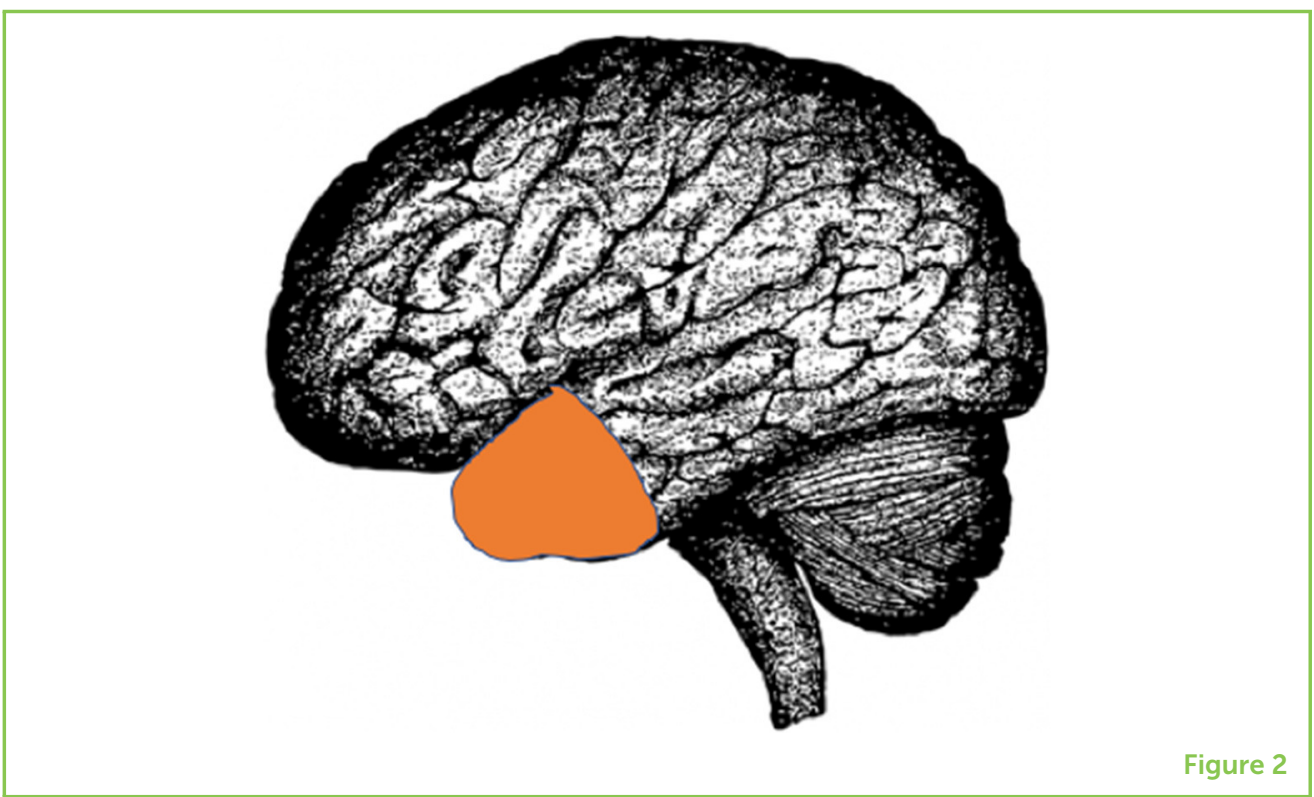

are coming from. In these operations, electrodes are placed into or on the surface of the brain. Electrodes are basically metal wires that conduct electricity, and they tell doctors when a seizure occurs. The surgeon places the wires in areas of the brain where the seizures are thought to occur. The electrodes stay there for several days while the person is in the hospital. During this time, doctors look at the electrical signals from these electrodes and try to decide where exactly in the brain the seizures are coming from. These operations do not actually treat the seizures, but they help doctors decide if there are any surgeries that may treat them.

Treatment surgeries are the second type of operation that can be done for seizures. The goal of treatment surgeries is to try to cure the seizures. There are three general types of operations that treat seizures. They include removing a part of the brain (Figure 2), disconnecting a part of the brain, and using electricity to stimulate the brain. Let us discuss each of these in turn.

First, if there is only one area in the brain that is causing seizures, then it makes sense that removing that area will cure the seizures. However, eloquent brain areas cannot be removed, because we cannot remove an important part of someone's brain. For example, if the area that is causing seizures is also responsible for allowing the person to walk, then we certainly cannot remove that brain area. Therefore, only areas of the brain that are not doing something important can be removed.

Second, if a large portion of the brain is causing seizures, the surgeon can disconnect that part from the rest of the brain [1]. For example, some people can have very bad seizures coming from an entire half of the brain. Often, that part of the brain is also no longer working. Rather 
Figure 3

An X-ray of a person's head showing a device to treat seizures. This device was placed inside the head through surgery and it stimulates the brain with electricity.

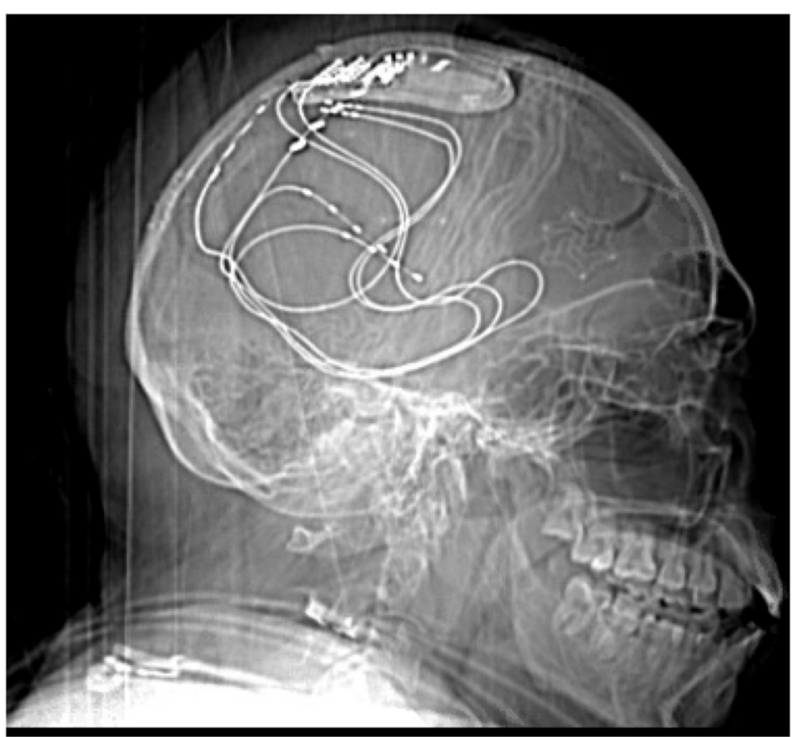

Figure 3

than removing an entire half of the brain, the surgeon can carefully disconnect the half that is causing seizures from the normal half. Despite this, patients can often still live relatively normal lives.

Third, using electricity to stimulate the brain is a newer way to treat some seizures [2]. When seizures are coming from more than one part of the brain, the surgeon can insert electrodes into those areas. These are different from the electrodes that are used to diagnose the seizures, because these electrodes are permanently left in the brain. These electrodes deliver a different type of electricity to the brain, and over time the person will have fewer and fewer seizures (Figure 3).

\section{SUMMARY}

From reading this article, I hope you have a better understanding of what seizures are and what can cause them. While many people have seizures that are treatable with medications, these medications unfortunately do not help all those who suffer from seizures. In those difficult cases, brain surgery can sometimes be used. There are many ways to treat seizures using brain surgery. Unfortunately, lots of people who have seizures do not know about the option of surgery, and they can go on having seizures for many years. If you know someone who has seizures that cannot be treated by medications, be sure to let them know that surgery might be an option for them. Encourage them to talk to their doctors specifically about surgery. Also, new ways to do brain operations and new medications are on the horizon. Researchers are always looking for new ways to treat seizures, and the future looks bright for those suffering from seizures. 


\section{REFERENCES}

1. De Ribaupierre, S., and Delalande, O. 2008. Hemispherotomy and other disconnective techniques. Neurosurg. Focus 25:E14. doi: 10.3171/FOC/ 2008/25/9/E14

2. Skarpaas, T. L., and Morrell, M. J. 2009. Intracranial stimulation therapy for epilepsy. Neurotherapeutics 6:238-43. doi: 10.1016/j.nurt.2009.01.022

SUBMITTED: 30 April 2020; ACCEPTED: 19 November 2020;

PUBLISHED ONLINE: 14 December 2020.

EDITED BY: Athina Tzovara, University of California, Berkeley, United States

CITATION: Girgis F (2020) Brain Surgery to Treat Seizures. Front. Young Minds 8:557949. doi: 10.3389/frym.2020.557949

CONFLICT OF INTEREST: The author declares that the research was conducted in the absence of any commercial or financial relationships that could be construed as a potential conflict of interest.

COPYRIGHT (c) 2020 Girgis. This is an open-access article distributed under the terms of the Creative Commons Attribution License (CC BY). The use, distribution or reproduction in other forums is permitted, provided the original author(s) and the copyright owner(s) are credited and that the original publication in this journal is cited, in accordance with accepted academic practice. No use, distribution or reproduction is permitted which does not comply with these terms.

\section{YOUNG REVIEWERS}

\section{ORGANIZATION FOR HUMAN BRAIN MAPPING, AGE: 8-15}

As part of the Kids Live Review Event at OHBM 2020, Adrian, Louie, Pinaki, Reina, and Tian, grilled the scientists on their work in front of an audience. This group of elite reviewers provided pointed feedback that improved the quality of each of these papers, ranging from boredom, irritability, and social learning, to brain surgeries and Alzheimer's disease.

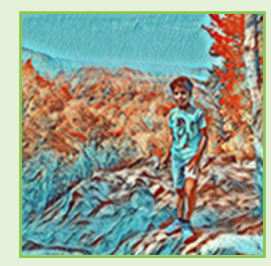

\section{PINAKI, AGE: 9}

Pinaki is in grade 4 at a French school. He likes basketball, reading, hip hop dancing, and playing with his friends. His favorite subjects in school are math and physical education. His favorite foods are pasta with pancetta and cheese, lasagne, and dumplings. His favorite songs right now are "Coffin Dance" and "Burning down the house." This was his first time being a reviewer for a science paper. 


\section{AUTHOR}

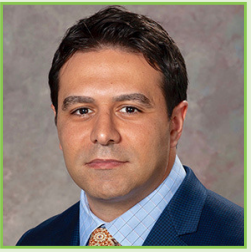

\section{FADY GIRGIS}

Fady Girgis is a neurosurgeon at the University of Calgary, in Canada. He performs surgery on the brains of people who have tremors, seizures, and brain tumors. $\mathrm{He}$ is also a scientist studying the electrical signals in our brains when we think and feel, and he is a teacher of medical students and other doctors training to be brain surgeons. He hopes to increase awareness of surgical treatment for seizures. *fadygirgis@yahoo.com 